\title{
Consent to publish is a matter of trust
}

\author{
John Fletcher MB BChir MPH, Diane Kelsall MD MEd
}

$\mathrm{W}$

hy do we ask authors to provide a consent form signed by the patient before we will publish an image or case history in $C M A J$ that might lead to the patient's identification? Consent is needed because the information contained in the article arose out of a confidential relationship in which the patient was receiving health care. Doctors may be used to discussing a patient's details in the relatively confidential setting of medical teaching or professional discussion, but publication in a journal makes those details accessible to the world. Patients have a right to privacy, and they trust that this privacy will not be breached without their permission. In the past, $C M A J$ sought to uphold this right by requiring authors to obtain written consent from patients on a $C M A J$ consent form and to provide this form to the journal before the article is accepted for publication.

There were several problems associated with this policy. First, by focusing on the requirement for a signature on a journal-specific form, it was easy to give the impression that the patient was entering into some form of agreement with the journal. In truth, consent takes place in the context of the doctor-patient relationship, and it is the doctor's duty, as author, to ensure that consent is fully informed and freely given. Journals can uphold standards of publication ethics, but editors cannot be present to check that the patient understood and was not coerced and that the signature was not forged. It is the author's duty to protect the patient's rights and the journal's duty to uphold best practice by encouraging authors to comply. Second, authors have often found it hard to obtain consent on a form specific to $C M A J$, because at the time of the original consultation, they were unsure which journal might eventually accept their article for publication. Approaching the patient some months or years later has not always been easy, and patients can find the contact intrusive. The alternative of obtaining several signatures on different journals' proprietary forms at the time of the initial consultation is bureaucratic and irksome. Last, and most prosaic, by keeping signed consent forms at CMAJ, we are not meeting some of the newer requirements for health care providers to protect the privacy of personal information held on their patients.

In the future, we will no longer require authors to provide us with signed forms giving the patient's consent to publish in $C M A J$. However, we will require that authors give written affirmation that they have obtained consent to publish from the patient and that this consent was fully informed, voluntary, written and is in the author's possession. In obtaining consent, authors should note that consent is required if there is any doubt about maintaining patient anonymity. For example, a

simple chest radiograph without specific linked patient information would often not require consent. But if the diagnosis were unusual or if some details of the patient's history such as age, sex or occupation were given that, along with the author's name and affiliation, might lead to identification of the patient, it would be necessary to obtain consent. Practically, this means that consent will be required for case reports, Clinical Images and other $C M A J$ articles where case descriptions are included.

Patients should be informed that the published article will be available to view by anyone in the world with a connection to the Internet. The article or parts of it may be republished in other journals or other formats, in addition to the original publication in CMAJ. For example, images in an article may be reproduced with permission and published in other journals, or CMAJ's publisher may package articles into collections in print or electronic formats.

Consent is specific to each article. An identifiable patient should see at least a draft of the article to be submitted and preferably the accepted version. Consent is voluntary and may be withdrawn by the patient at any time before publication has occurred. Withholding or withdrawing consent should not affect the health care received.

Consent to publish is different from consenting to participate in research. Even if a patient has provided consent to participate in a research study, it is necessary to obtain consent to publish if there is any possibility the patient might be identifiable.

To help authors meet the standards of best practice, we recommend they use CMAJ's consent forms, which are available in several languages on our website (cmaj.ca). If any dispute or doubt arises concerning patient privacy and consent to publish, we will ask authors to provide proof of consent. Authors therefore have a duty to archive and protect these signed patient consent forms and to inform patients of their rights.

By obtaining fully informed, written consent to publish and by keeping it in their possession, physicians can assure their patients that the confidentiality essential to the doctor-patient relationship is paramount. When patients consent to have their medical details shared for the betterment of others, it is a trust that cannot be taken lightly.

Competing interests: See www.cmaj.ca/site/misc/cmaj_staff.xhtml

Affiliation: John Fletcher is Editor-in-Chief and Diane Kelsall is Deputy Editor, Clinical, CMAJ.

Correspondence to: $C M A J$ editor, pubs@cmaj.ca

CMAJ 2014. DOI:10.1503/cmaj.140165 